\title{
BMJ Open Climatic and community sociodemographic factors associated with remote Indigenous Australian smoking rates: an ecological study of health audit data
}

\author{
Suzanne Jane Carroll, ${ }^{1}$ Michael J Dale, ${ }^{\oplus 1}$ Ross Bailie, ${ }^{2}$ Mark Daniel ${ }^{1,3}$
}

To cite: Carroll SJ, Dale MJ, Bailie R, et al. Climatic and community sociodemographic factors associated with remote Indigenous Australian smoking rates: an ecological study of health audit data. BMJ Open 2019;9:e032173. doi:10.1136/ bmjopen-2019-032173

- Prepublication history for this paper is available online. To view these files, please visit the journal online (http://dx.doi org/10.1136/bmjopen-2019032173).

Received 6 June 2019 Accepted 7 June 2019

\section{Check for updates}

(C) Author(s) (or their employer(s)) 2019. Re-use permitted under CC BY-NC. No commercial re-use. See rights and permissions. Published by BMJ.

${ }^{1}$ Centre for Research and Action in Public Health, Health Research Institute, University of Canberra, Canberra, Australian Capital Territory, Australia

${ }^{2}$ University Centre for Rural Health, The University of Sydney, Lismore, New South Wales, Australia

${ }^{3}$ Department of Medicine, St. Vincent's Hospital, The University of Melbourne, Fitzroy, Victoria, Australia

Correspondence to Professor Mark Daniel; mark.daniel@canberra.edu.au

\section{ABSTRACT}

Australian Indigenous smoking rates are highest in remote communities but likely vary between communities; few studies have assessed community features in relation to Indigenous smoking rates.

Design and objective This ecological study evaluated the associations between smoking rates, and community sociodemographic and climatic characteristics for a large sample of remote Indigenous communities.

Setting and sample Records $(n=2689)$ from an audit of community health centres in the Northern Territory and Queensland were used to estimate smoking rates dichotomised at the median for 70 predominantly Indigenous remote communities. Community characteristics were similarly dichotomised. Methods Cross-tabulations were used to calculate the odds of a community classified as high for a sociodemographic or climatic factor also being high for smoking rate. Additional cross-tabulations, stratified by sociodemographic, region (coastal or central) and geographic connectivity levels, were performed to assess potential confounding.

Results Community smoking rates ranged from $25 \%$ to $96 \%$ (median $60.2 \%$ ). Moderately strong relationships were observed between community smoking rate and population size (OR 6.25,(95\% Cl 2.18 to 17.95)), education level (OR 3.67 (1.35-10.01)), income (2.86 (11.07-7.67)) and heat (2.86 (1.07-7.67)).

Conclusions Smoking rates in Australian remote Indigenous communities are universally high. Smoking rates are associated with greater community-level socioeconomic status and size, most likely reflecting greater means of accessing tobacco with mass of smokers sufficient to sustain a normative influence. Severe heat was also associated with high smoking rates suggesting such a stressor might support smoking as a coping mechanism. Community sociodemographic and climatic factors bear consideration as context-level correlates of community smoking rates.

\section{INTRODUCTION}

Tobacco smoking is a major risk factor for a range of chronic health conditions including
Strengths and limitations of this study

- This study contributes to the limited literature on smoking rates in remote Australian Indigenous communities which thus far has been based on considerably smaller samples of communities.

- This study is unique in estimating ecological associations between smoking rates and relevant community-level sociodemographic, geographic and climatic factors.

- Community smoking rates derived from health service data were linked with census, geographic connectivity and climatic information.

- Sample loss due to missing smoking information most likely indicates random deficiencies in health assessment at the local level, thus biassing results towards the null.

- Study results are generalisable to Australian remote Indigenous communities and may be broadly generalisable to remote-dwelling indigenous populations in other developed countries.

cardiovascular disease, type 2 diabetes and cancer. ${ }^{12}$ Indigenous populations worldwide have higher smoking rates than non-Indigenous populations. Disparities in smoking prevalence are apparent in New Zealand (Maori $35.5 \%$; New Zealand adults $14.2 \%$ ), the USA (American Indians/Alaska Natives 29.2\%; US adults $16.8 \%$ ) and Canada (First Nations, off-reserve 26.8\%; Inuit $48.9 \%$; Canadian non-Aboriginal population 15.1\%).${ }^{3-5}$ In Australia, Aboriginal and Torres Strait Islander peoples (hereafter Indigenous Australians) are 2.7 times as likely to smoke daily as non-Indigenous Australians, with age-standardised prevalence rates of $42 \%$ and $15 \%$, respectively. ${ }^{6}$ Tobacco-related conditions are estimated to account for half of the health gap between Indigenous and non-Indigenous Australians. ${ }^{7}$ 
Greater smoking in Indigenous Australians has been attributed to socioeconomic factors (low income, financial stress, unemployment, low education and housing (rental versus ownership, overcrowding)); sociocultural factors (smoking exposure and normalisation); social factors (boredom, or being: arrested; incarcerated; removed from family (or removal of a relative); a victim of violence or threats); and stress, including stress associated with a history of colonisation and dispossession (racism, marginalisation, family dislocation, disconnection from the land, loss of traditional diet and lifestyle and the adoption of Western habits and practices). ${ }^{8-10}$

Adult Indigenous Australian smoking rates vary from $39 \%$ in major cities to $49 \%$ in remote and $56 \%$ in very remote areas. ${ }^{11}{ }^{12}$ This is unsurprising given smoking varies by social disadvantage ${ }^{9}$ and, in Australia, social inclusion and socioeconomic status lessen with distance from major metropolitan areas. ${ }^{13}$ Thus, it is reasonable to anticipate greater smoking amongst Indigenous Australians in more remote regions.

Smoking rates also differ between remote Indigenous communities with one study reporting rates ranging from $59 \%$ to $80 \%$. $^{14}$ This variation may be driven by community-specific factors. In research not focused on Indigenous communities, factors such as neighbourhood disadvantage, perceived crime and neighbourhood stress, and perceived acceptability of smoking have been linked to greater likelihood of an individual smoking. ${ }^{15-17}$ Thus, variation in community exposures may shape differences in smoking behaviours between remote Indigenous communities, yielding differences in consequent disease outcomes. Specific to Indigenous smoking, geographic variation in smoking rates (ie, generally higher smoking rates in northern coastal regions) has been attributed to historical factors, with smoking behaviour introduced across the northern coastal region of Australia by Macassan fishermen ${ }^{10} 18$ beginning around $1780 .{ }^{19}$ Minimal research has investigated differences between Indigenous communities, despite geographic variations in smoking rates that likely reflect geographic variation in environmental predisposing factors.

A further potential influence on smoking prevalence is extreme weather, which is demonstrably 'more extreme' in remote Australian regions. Temperature extremes can vary from $34.8^{\circ} \mathrm{C}$ to $38.0^{\circ} \mathrm{C}$ in the Darwin (metropolitan) region, to $42.0^{\circ} \mathrm{C}$ to $46.3^{\circ} \mathrm{C}$ in the remote Rabbit Flat region. ${ }^{20}$ Cigarette sales across the US demonstrate seasonality, increasing in the summer months, ${ }^{21}$ with this pattern also evident within smaller geographic areas (ie, within New Jersey). ${ }^{22}$ This apparent association between temperature (higher in summer months) and smoking may be the result of the relationship between extreme high temperatures and negative affective states, stress and violence, ${ }^{2324}$ as stress is well accepted as being linked to smoking. ${ }^{925}{ }^{26}$ Extreme high temperatures may influence smoking behaviour by increasing stress and anxiety levels.

Tobacco use is of major significance to the health gap affecting Indigenous Australians and is highest in socially disadvantaged populations in geographically remote locations. Few studies have assessed community exposures in relation to Indigenous smoking behaviour. This study assessed smoking rates for remote Indigenous communities in relation to community sociodemographic and climatic factors.

\section{METHODS}

This study is part of the Environments and Remote Indigenous Cardiometabolic Health Project which aimed to identify community features related to the cardiometabolic health of Indigenous Australians living within remote communities across the Northern Territory and Queensland. This study was conducted in accordance with the principles of the Declaration of Helsinki. Ethics approvals were obtained from multiple Human Research Ethics Committees (details in Ethics approval section).

\section{Sampling}

This study used community health service records from the One21seventy program, applying protocols for auditing of preventive healthcare developed by the Audit and Best Practice for Chronic Disease (ABCD) Project. ${ }^{27}$ The ABCD Audit Protocols defines community health service client records eligible for audit via the following criteria: (1) aged between 15 and 54 years; (2) a community resident for $\geq 6$ months per last 12 months; (3) not previously diagnosed with diabetes, cardiovascular disease or chronic kidney disease; and (4) not pregnant or $<6$ weeks postpartum. The audit sample was drawn from the identified eligible client records with sample size determined according to program recommendations. ${ }^{27}$ Where there were more than 30 eligible records, records were randomly sampled with the size of the sample determined by a sliding scale based on the number of eligible records. Where the number of eligible client records was 30 or less, all records were sampled.

The current study accessed audit data according to the following inclusion criteria, the community was: (1) located within the Northern Territory or Queensland; (2) a 'remote' location ${ }^{28}$; and (3) a predominantly Indigenous community signed up to the ABCD National Research Partnership. Such communities were assigned a unique spatial identifier, allowing linkage with other datasets including Australian Bureau of Statistics (ABS) Census data expressed for Indigenous Locations (ILOCs). ${ }^{28}$ ILOCs are the smallest resolution at which Indigenous Census data are available, typically representing small (minimum 90 persons) Indigenous communities. Some $(n=3)$ ILOCs include multiple nearby and associated very small communities. Communities belonging to such ILOCs were excluded from this study. Seventy communities met the above inclusion criteria and were included in this study.

Audit data for the years 2010-2014 were extracted for each community (total $\mathrm{n}=8561$ records). Audit records were assessed for multiple client coverage using date 
of birth and sex, with the most recent record retained $(\mathrm{n}=5412)$. Records were excluded where the clients identified as 'Neither' an Aboriginal and/or Torres Strait Islander person $(\mathrm{n}=337)$ and clients whose last health centre attendance was prior to 1 January $2010(n=395)$, leaving 4680 records remaining. Audit data were aggregated by community.

\section{Patient and public involvement}

Due to the reliance of this study on audit data of health service record, patients and the public were not involved in the design or execution of this research. However, sampled communities were extensively consulted and voluntarily participated in the One21Seventy program from which health record audit data were sourced.

\section{Measures}

Dependent variable

Community smoking rates were calculated from audit records. For each community, smoking rate was calculated as the count of clinical records documenting status as 'smoker' divided by the total records with a valid smoking status (ie, sum of 'smoker' and 'non-smoker'). Where smoking status was not recorded (ie, 'no record' or 'not applicable') the audit record was excluded ( $n=1991)$, leaving a final sample of 2689 records of Indigenous Australians with an identifiable smoking status.

\section{Independent variables}

Community-level Indigenous sociodemographic data were extracted from the ABS 2011 Population and Housing Census $^{29}$ and expressed at the ILOC spatial unit. ${ }^{28}$ Data included: population size (all persons); count of Aboriginal and Torres Strait Islander persons; age (median); overcrowding (the percentage of dwellings requiring one or more additional bedrooms based on household demographics); and income (median household). Proportions of Indigenous persons were calculated from the Census data for education (grade 10 schooling or higher) and employment (aged 15 years and over in labour force).

Geographic connectivity was expressed as a count of other Indigenous communities within a $250 \mathrm{~km}$ road-network distance $^{30}$ (mainland communities only; $\mathrm{n}=56$ ).

Climate profiles were obtained from surface maps sourced from the Australian Bureau of Meteorology for the period 1961-2012 $2^{31}$. Community-level climate measures representing heat and heavy rain were determined as follows. Heat was operationalised as the average of the annual sum of 'cooling degree.days' in each community. 'Cooling degree.days' is a standard measure ${ }^{32}$ defined as the number of degrees by which a day's mean temperature exceeds $18^{\circ} \mathrm{C}$. For example, a day with a mean daily temperature of $25^{\circ} \mathrm{C}$ would attract a cooling degree.days score of 7 degree.days, whereas as day with a mean daily temperature of $16^{\circ} \mathrm{C}$ would attract a score of 0 degree.days. Heavy Rain was operationalised as the mean of the annual number of days with greater than $25 \mathrm{~mm}$ of precipitation.
Region was determined according to the community geographic location within Australian Bureau of Meteorology Climate Zones, ${ }^{33}$ with the climate zones 'Equatorial' and 'Tropical' collapsed to form the 'Coastal' Region, and the climates zones 'Desert' and 'Grassland' collapsed to form the 'Central' Region. Of the 70 included remote communities, 43 were classified as Coastal and 27 as Central.

\section{Data preparation}

Communities were classified as 'high' or 'low' based on the median community value for each variable except Region (classification defined above) (table 1). Alternative cut points were considered, such as the 25th and 75th percentiles;however, use of other cut points resulted in very small cell sizes, particularly within stratified cross-tabulations, such that some cells included zero counts.

\section{Statistical analysis}

ORs were calculated by two-by-two cross-tabulations of counts of communities classified as high or low smoking rate and counts of communities with high or low classifications of sociodemographic and climatic variables. Additional two-by-two cross-tabulations stratified by community-level measures (sociodemographic measures, geographic connectivity and region) were conducted to assess potential confounding. Where the stratified groups were homogeneous (Breslow-Day test of homogeneity of ORs), adjusted pooled ORs were calculated using the mid- $p$ method. Due to small counts within cells, 'exact' options (mid- $p$ and mid- $p$ 95\% CIs) were used throughout. ${ }^{34}$ All data preparation and analyses were conducted in SAS (V.9.4) and WinPepi (Compare2, V.3.85, J. Abramson).

\section{RESULTS}

Features of communities are described in table 1. Median population size was 332. Median population proportion identifying as Indigenous (ie, Aboriginal and/or Torres Strait Islander) was $90.7 \%$. Median smoking rate was $60.2 \%$ with a large range $(25.0 \%-96.0 \%)$.

Table 2 reports the results of the two-by-two (presented highest to lowest magnitude of OR) and stratified two-by-two cross-tabulations. Relatively high population communities were more likely to have high smoking rates (OR 6.25, (95\% CI 2.18 to 17.95), $\mathrm{p}<0.001$ ) compared with communities with low population size. Stratification into high and low conditions for sociodemographic measures and geographic connectivity revealed no differences in ORs between conditions (Breslow-Day test of homogeneity $\mathrm{p}>0.05)$ and pooled ORs remained moderately large (ORs ranging from 5.35 to 6.88 , p values $<0.01$ or smaller) though with greater attenuation when accounting for region (OR 4.43 (1.47-13.92], $\mathrm{p}<0.01)$.

High education communities were more likely to have high smoking rates (OR 3.67 (1.35-10.01], $\mathrm{p}=0.010$ ) than communities with low education. Stratification 


\begin{tabular}{|c|c|c|c|c|c|}
\hline Community feature & Mean & Median & IQR & Min & Max \\
\hline Population size (Count of total persons*) & 522.9 & 331.5 & $210.0-686.0$ & 111 & 2124 \\
\hline $\begin{array}{l}\text { Indigenous persons (as proportion of total } \\
\text { persons } ; \% \text { ) }\end{array}$ & 87.8 & 90.7 & $88.0-94.0$ & 52.2 & 100.0 \\
\hline \multicolumn{6}{|l|}{ Indigenous persons: } \\
\hline $\begin{array}{l}\text { Proportion who are smokers (\% of audited } \\
\text { records) }\end{array}$ & 59.5 & 60.2 & $50.0-70.0$ & 25.0 & 96.0 \\
\hline Age (median*; years) & 23.0 & 22.0 & $20.0-25.0$ & 16.0 & 31.0 \\
\hline Income (median household*; AUD/week) & 952.41 & 912.00 & $722.00-1125.00$ & 312.00 & 2111.00 \\
\hline $\begin{array}{l}\text { Education (proportion with year } 10 \\
\text { schooling or greater*; \%) }\end{array}$ & 55.3 & 58.2 & $36.8-73.1$ & 9.4 & 85.2 \\
\hline Employment (proportion in labour force*; \%) & 38.3 & 34.6 & $27.6-52.0$ & 10.7 & 73.5 \\
\hline $\begin{array}{l}\text { Overcrowding (proportion of households } \\
\text { requiring additional bedrooms*) }\end{array}$ & 44.8 & 43.1 & $31.1-60.0$ & 11.6 & 84.4 \\
\hline $\begin{array}{l}\text { Geographic connectivity (count of Indigenous } \\
\text { communities within } 250 \text { kmt-road network } \\
\text { distance) }\end{array}$ & 10.8 & 6.0 & $4.0-14.0$ & 2.0 & 39.0 \\
\hline Heat (average annual cooling degree.days) $\ddagger$ & 2908.5 & 3178.0 & 2293-3353 & 1678.0 & 3644.0 \\
\hline $\begin{array}{l}\text { Heavy rain (average annual number of days } \\
\text { with greater than } 25 \mathrm{~mm} \text { of precipitation, } \\
\text { days/year) }\end{array}$ & 14.4 & 15.7 & $4.2-24.4$ & 2.4 & 25.6 \\
\hline
\end{tabular}

${ }^{*}$ Data relate to the ILOC associated with the selected community.

$\dagger \mathrm{t}=56$ (mainland communities only).

†Heat, cooling degree.days is calculated as the average of the annual sum of the number of degrees by which each day's mean temperature exceeds $18^{\circ} \mathrm{C}$.

AUD, Australian Dollars; ILOC, Indigenous Locations.

by geographic connectivity and employment revealed differences in ORs between the high and low conditions. Amongst communities with high geographic connectivity, high community-level education was associated with high smoking rates $(\mathrm{OR} \infty[2.68-\infty], \mathrm{p}=0.002)$. This relationship was not statistically significant among communities with low geographic connectivity. Similarly, amongst communities with low employment, the odds of high education communities being high in smoking rate rose strongly (OR 26.67 (3.03-621.30], $\mathrm{p}<0.001)$ while there was no statistically significant association with the high employment condition. Pooled ORs for high education communities being high in smoking rate, after accounting for other measures, were small to moderate (OR 3.47$6.45, \mathrm{p}<0.05$ or smaller), except when accounting for region when the association became null. This reflects the differing directions of associations between regions though the difference between groups did not quite reach statistical significance (Breslow-Day test of homogeneity $\mathrm{p}=0.066$ ).

Communities with frequent heavy rain were more likely to have high smoking rates (OR 3.67 (1.35-10.01], $\mathrm{p}=0.010$ ). These odds were greater for communities with an older population (OR 18.20 (2.96-139.00], $\mathrm{p}<0.001)$ or low education (OR 10.50 (1.61-84.86], $\mathrm{p}=0.006$ ) while the odds became non-significant for communities with a younger population or high education. Pooled
ORs remained of small to moderate strength when accounting for household income (OR 3.51 (1.28-10.05) $\mathrm{p}=0.014)$, employment (OR 3.12 (1.03-9.89], $\mathrm{p}=0.043)$, overcrowding (OR 4.67 (1.51-16.28) $\mathrm{p}=0.007$ ), and geographic connectivity (OR $7.45(1.86-33.39) \mathrm{p}=0.004)$. However, on accounting for population size the odds of communities with frequent heavy rain being high in smoking rate were non-significant. When stratifying by region, no central communities were classified as having frequent heavy rain and the association between frequent heavy rain and smoking was null for the coastal communities.

Community income was associated with smoking rate (OR 2.86 (1.07-7.67], $\mathrm{p}=0.036)$. Stratification into high and low conditions for sociodemographic measures and geographic connectivity revealed no differences in ORs between groups, and pooled ORs were small to moderate (range 2.31-3.75) but were not statistically significant when accounting for population size, geographic connectivity, or region.

Heat was also associated with community smoking rate (OR $2.86(1.07-7.67], \mathrm{p}=0.036)$ and the odds of a hotter climate community being high in smoking rose notably under the following conditions: low education (OR 13.33 (2.30-79.93], $\mathrm{p}=0.001$ ); low employment (OR 12.67 (2.06-98.54) $\mathrm{p}=0.004)$, high overcrowding (OR 9.17 (1.82-50.20], $\mathrm{p}=0.004)$, high connectivity 


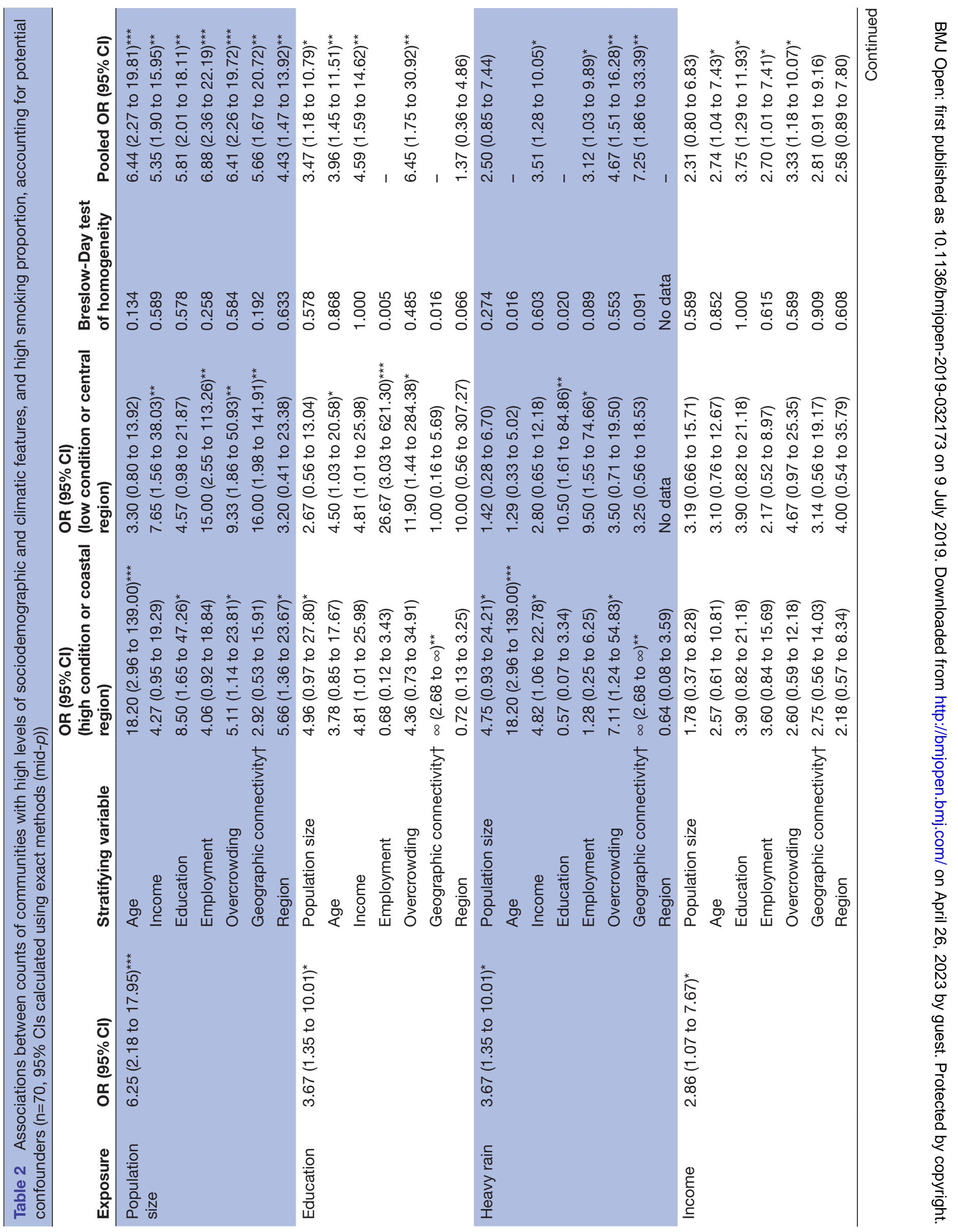




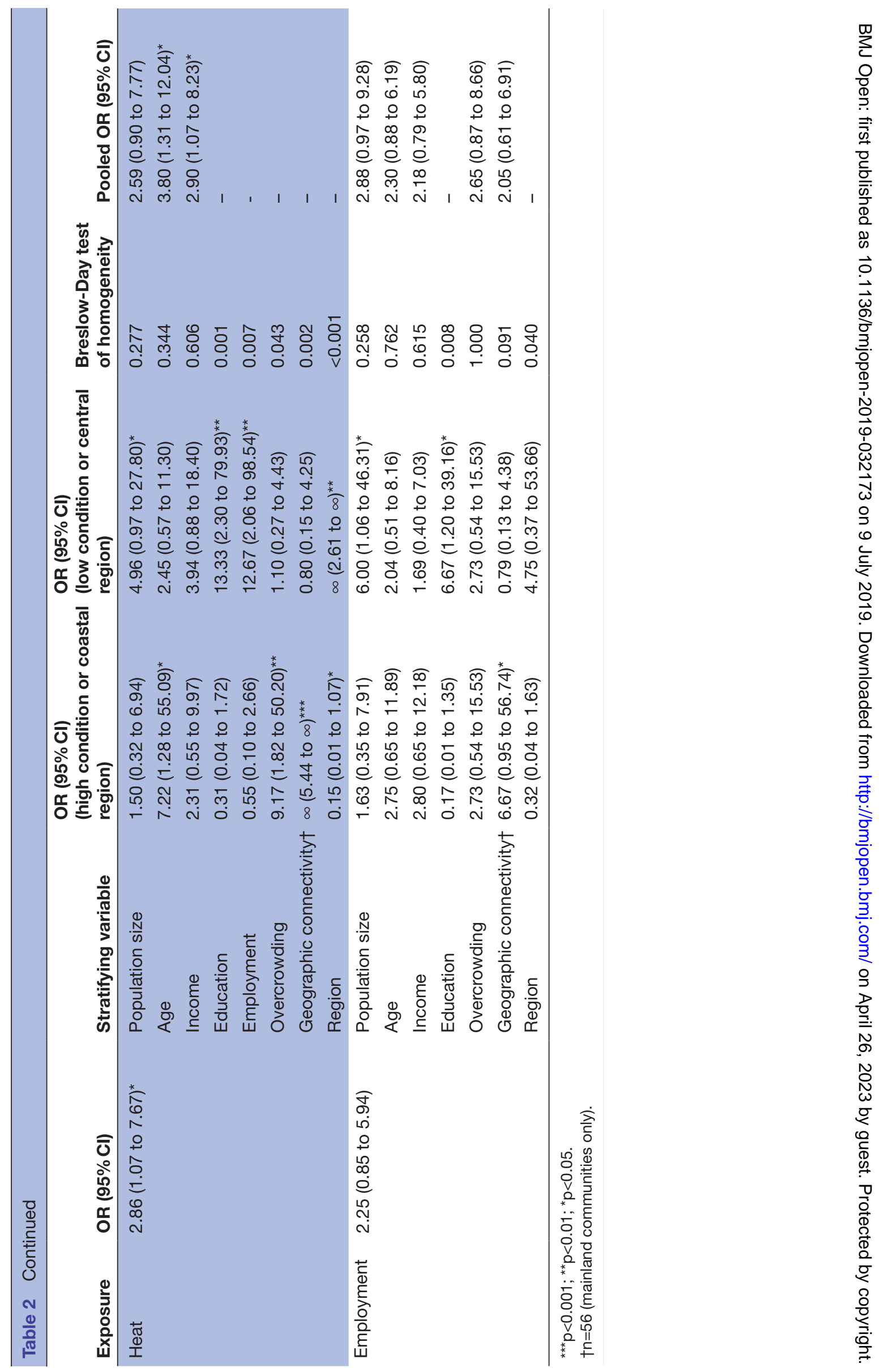


$(\mathrm{OR} \infty[5.44-\infty], \mathrm{p}<0.001)$, and central region $(\mathrm{OR} \infty$ $[2.61-\infty], \mathrm{p}<0.01)$. Amongst coastal communities, high heat was associated with a lesser likelihood of being a high smoking community (OR 0.15 (0.01-1.07], p<0.05). Pooled ORs were small to moderate when accounting for average population age (OR $3.80(1.31-12.04) \mathrm{p}=0.013)$, and income (OR $2.90(1.07-8.23) \mathrm{p}=0.036)$ but there was no statistically significant association when accounting for population size.

Community employment was not associated with smoking rate (OR $2.25(0.85-5.94], \mathrm{p}=0.103)$ but under the low community education condition the odds of high employment communities being high in smoking rose substantially (OR 6.67 (1.20-39.16], p=0.026). Stratifying by location revealed ORs differing in directions. Amongst coastal communities, high employment rate was inversely associated with smoking rate (OR 0.32 (0.041.63)) while amongst central communities, high employment was directly associated with high smoking rate (OR $4.75(0.37-53.66))$. These region-specific associations, however, did not reach statistical significance. Pooled ORs accounting for other sociodemographic measures or geographic connectivity yielded small but statistically non-significant effects (ORs ranging from 2.05 to 2.88).

\section{DISCUSSION}

This ecological study assessed Indigenous Australian smoking rates based on health-audit records, within predominantly Indigenous remote communities, in relation to community-level sociodemographic and climatic factors. We observed substantial variation in Indigenous smoking rates between remote communities, from $25 \%$ to $96 \%$, a broader range than previously reported. Other studies reported rates as ranging between $59 \%$ to $80 \%^{14}$ and $27 \%$ to $68 \% .^{35}$

Our observed variation may be, in part, due to the large degree of sample loss resulting from audit client records missing smoking information. Wright and colleagues ${ }^{35}$ noted particularly small sample sizes available for some Indigenous regions which may impact on the precision of estimates and artificially inflate the range of smoking rates reported. To better understand geographic variation in smoking rate, its associated factors, and change in rates over time, better quality data are needed. Regardless, our findings align with previously identified substantial geographic variation in smoking between remote Indigenous communities. This variation has important implications for intervention strategies, suggesting the need for localised approaches targeting communities according to smoking prevalence. It is, however, important to note that regional variation in smoking rates has a basis in the history of tobacco usage among Indigenous Australians, with exposure to smoked tobacco (in contrast to the custom of chewing native, nicotine-containing flora) preceding Western colonisation and occurring in littoral regions of the Northern Territory and Queensland via trade. ${ }^{10}$ This study stratified cross-tabulations by region in order to account for this previously established variation in smoking rates.

Our findings indicate smoking rate covaries with community-level features, notably, population size, education level, income, heat and frequency of heavy rain. Some effects varied given other community conditions. Communities with larger populations were more likely to have high smoking rates. This may reflect greater access to cigarettes as larger communities likely have more services including retail outlets for cigarettes. Relatively high-income communities were also more likely to have high smoking rates, suggesting greater ability to afford cigarettes. This association was nullified, however, by accounting for population size, geographic connectivity, and region (itself related to both population size and geographic connectivity), given that with greater population size and geographic connectivity comes greater income earning opportunity.

Communities with a relatively high education level were more likely to have high smoking rates, particularly if the community also had low levels of employment or high geographic connectivity to other Indigenous communities. The direction of this relationship is unexpected, as individual-level education and area-level SES are both inversely related to individual smoking in the Australian population in general, and Indigenous Australians in particular. ${ }^{36}{ }^{37}$ Greater education with lesser opportunity to apply that education through employment could, however, constitute a substantial stressor that supports smoking as a coping strategy.

It is possible that relationships observed between community smoking rate and sociodemographic features (population size and education level) reflect complex historic and ongoing social pathologies. Larger communities may consist of multiple displaced, and sometimes feuding, family groups forcefully relocated from their traditional homelands to a mission site. ${ }^{38}$ Forced removal from traditional lands breaks the important connection that Indigenous Australians have to Country, a connection important to their well-being. ${ }^{39}$ Moreover, forced dispossession and resettlement disrupted established traditional lifestyles and social systems whilst failing to provide an adequate alternate cultural system, resulting in reduced quality of lifestyle. ${ }^{40}$

This disruption of traditional structures and inadequate replacement with new structures, and the lack of acceptance into the western social system could lead to anomie and collective despondency, exacerbated by cultural bereavement. ${ }^{41-43}$ It follows that such communities would have higher smoking rates amongst other social problems. Indeed, communities with a long history of receiving forcefully displaced groups and where maximum dysfunctional cultural change has occurred are most likely to exhibit social pathologies and disorder, including violence and self-harm. ${ }^{40}$ We speculate that the unexpected association found in this study between high education and high smoking rate, particularly in communities with low employment, exemplifies the lack of social 
integration and acceptance into western social structures and resultant coping behaviour.

Relatively high community-level Western-style education may correspond to a reduced reliance on traditional social structures. Yet, higher levels of education may not overcome institutional racism and enable Indigenous individuals and groups to be truly accepted within the broader, non-Indigenous societal structures and take advantage of related opportunities. This latter point would be highlighted to the individual and the community by lack of employment. Smoking rate is likely a symptom of the broader issues faced by remote Indigenous communities and attempts to reduce smoking without considering these broader issues are unlikely to be effective. Interventions targeting proximal individual-level determinants of smoking need to be supported by efforts to improve distal community-level and societal factors. ${ }^{44}$ Broad ecological approaches collaborating with local Indigenous representatives to facilitate local empowerment are needed with the focus on reducing the underlying social problems and ensuing social psychological states that predispose individual smoking behaviours. ${ }^{26}$

Regarding climatic exposures, the influence of weather on smoking has rarely been assessed, especially in Indigenous populations. We observed frequent heavy rain to be associated with high smoking rates, particularly where community residents had a higher median age. However, this relationship may be an artefact of the association between region and smoking, as frequent heavy rain occurred only in the coastal region, and coastal communities were more likely to be high in smoking rate. Heat was also associated with high smoking rates, particularly in communities with low education, low employment, high overcrowding, high geographic connectivity and central region. This supports our premise regarding heat as a stressor affecting smoking behaviour, an effect seemingly compounded by other adverse conditions. In particular, the strong positive relationship between high heat and smoking in the central region suggests the relationship between heat and smoking rate is not due to confounding by region. If stress due to ongoing, inescapable heat is indeed related to smoking, as our findings suggest, this supports the need for better quality, culturally appropriate housing to ameliorate such stress. It is possible, however, that the apparent association between heat and smoking rate is due to other factors not measured here. These associations are novel and warrant further exploration.

This study builds on and expands the literature on Australian Indigenous smoking as few studies have assessed smoking rates of remote Indigenous communities, especially in relation to community-level factors. It identifies relationships between community smoking rate and community features and provides a snapshot of smoking rates in remote Indigenous communities. Though specific to Australian remote Indigenous communities, these findings may be broadly generalisable to other remote-dwelling indigenous populations in high-income countries as such populations have similar characteristics and have experienced similar historical exposures. Some limitations should be noted. The cross-sectional nature of this study limits inference on the temporal direction of associations. Use of clinical audit data only captures information for individuals who accessed western healthcare services. Individual-level audit record sample loss due to missing smoking information may have introduced bias to the data and be indicative of deficient health assessment and data collection procedures at the local health service level. Similarly, the use of audit records creates a selection bias (eg, not including records with chronic diseases) hence our results likely under-estimate the prevalence of smoking. Limitations in the assessment of community-level smoking have been noted in other studies. ${ }^{35} 45$ Potential confounding due to residential self-selection toward smaller and potentially healthier communities could not be accounted for. Given the small sample size and the desire to assess simple associations, the common and recommended ${ }^{46}$ epidemiological approach of dichotomising the data at the median was utilised. We acknowledge that the categorisation of these data results in some information loss. Finally, this study is ecological and associations between community smoking rates and community factors should not be inferred at the individual level. The environmental correlates of smoking rates stand to differ from the predictors of individual smoking initiation and cessation.

\section{CONCLUSION}

This study found substantial variation in smoking rates between Australian remote Indigenous communities, and that community-level sociodemographic (relatively large population size, high education level and high income), and climatic factors (heat and frequent heavy rain) were associated with high smoking rates. Better data are needed to more accurately assess differences in community smoking rates, the ecological factors relating to these differences, and to track change in smoking rates over time. Further assessment of climatic factors, particularly heat, in relation to smoking is warranted. Community smoking rate is likely associated with adverse historical experiences and local pathologies. Efforts to reduce smoking rates should include a focus on improving local social conditions using a collaborative approach distinct from traditional forms of health education.

Acknowledgements The authors wish to acknowledge Veronica Matthews, Senior Research Officer, ABCD National Research Partnership for assistance in data provision. The development of this manuscript would not have been possible without the active support, enthusiasm and commitment of staff in participating primary health care services, and members of the ABCD National Research Partnership and the Centre for Research Excellence in Integrated Quality Improvement.

Contributors SJC prepared the data, performed analyses, interpreted results and contributed to the drafting and revision of the manuscript. MJD performed analyses, interpreted results and contributed to the drafting and revision of the manuscript. RB conceived of and designed the study and contributed to the revision of the manuscript. MD conceived of and designed the study, interpreted results and 
contributed to the drafting and revision of the manuscript. All authors approved the final manuscript.

Funding This work was supported by the Australian Research Council [grant number DP120102482] and drew upon data collected as part of the One21seventy project. One21 seventy is a continuous quality improvement (CQI) program developed as part of the ABCD National Research Partnership Project (both the ABCD National Research Partnership Project and the Centre for Research Excellence in Integrated Quality Improvement were funded by the National Health and Medical Research Council [GNT545267; GNT1078927, respectively] and the Lowitja Institute, and by financial and in-kind support from a range of Community Controlled and Government agencies). The Audit and Best Practice for Chronic Disease Extension (ABCDE) Project was supported by funding from the Cooperative Research Centre for Aboriginal Health and the Australian Commission on Safety and Quality in Health Care. The funding sources had no involvement with study design, data collection, analysis and interpretation of results, writing this manuscript or choice of journal.

Competing interests None declared.

Patient consent for publication Not required.

Ethics approval Ethics approval for the present study was obtained from the Human Research Ethics Committee (HREC) of University of South Australia [HREC Reference No. 31874], Central Australian Human Research Ethics Committee [HREC-13-182], Human Research Ethics Committee of the Northern Territory Department of Health and Menzies School of Health Research [HREC 20132083], and Far North Queensland Human Research Ethics Committee [HREC/15/ QCH/4-946]. Ethics approvals for the ABCD National Research Partnership, for the geographic area pertaining to this study, were obtained from HRECs in the states and territories involved: the HREC of the Northern Territory Department of Health and Menzies School of Health Research (HREC-EC00153); Central Australian HREC (HREC-12-53); Queensland HREC Darling Downs Health Services District (HREC/11/ QTDD/47); and the South Australian Indigenous Health Research Ethics Committee (04-10-319). Protocols for sharing deidentified client-level data by participating health services are managed by the ABCD National Research Partnership.

Provenance and peer review Not commissioned; externally peer reviewed.

Data sharing statement Data are available upon request.

Open access This is an open access article distributed in accordance with the Creative Commons Attribution Non Commercial (CC BY-NC 4.0) license, which permits others to distribute, remix, adapt, build upon this work non-commercially, and license their derivative works on different terms, provided the original work is properly cited, appropriate credit is given, any changes made indicated, and the use is non-commercial. See: http://creativecommons.org/licenses/by-nc/4.0/.

\section{REFERENCES}

1. CDC. How tobacco smoke causes disease: the biology and behavioral basis for smoking-attributable disease: a report of the Surgeon General. Atlanta, GA: Centers for Disease Control and Prevention (US), 2010.

2. Willi C, Bodenmann P, Ghali WA, et al. Active smoking and the risk of type 2 diabetes: a systematic review and meta-analysis. JAMA 2007;298:2654-64.

3. Jamal A, Homa DM, O'Connor E, et al. Current cigarette smoking among adults - United States, 2005-2014. MMWR Morb Mortal Wkly Rep 2015;64:1233-40.

4. Statistics Canada. Aboriginal statistics at a glance. 2nd ed. Canada: Statistics Canada, 2015.

5. Ministry of Health. Annual update of key results 2015/16: New Zealand Health Survey. Wellington: Ministry of Health, 2016.

6. AlHW. Australia's health 2018. Australia's health series no. 16. ed. Canberra: AlHW, 2018.

7. Vos T, Barker B, Begg S, et al. Burden of disease and injury in Aboriginal and Torres Strait Islander Peoples: the Indigenous health gap. Int J Epidemiol 2009;38:470-7.

8. Briggs VL, Lindorff KJ, Ivers RG. Aboriginal and Torres Strait Islander Australians and tobacco. Tob Control 2003;12 Suppl 2(Suppl 2):ii5-ii8.

9. Thomas DP, Briggs V, Anderson IP, et al. The social determinants of being an Indigenous non-smoker. Aust N Z J Public Health 2008;32:110-6.

10. Scollo M, Winstanley M. Tobacco in Australia: facts and issues. Melbourne, Australia: Cancer Council Victoria, 2017. http://www. TobaccolnAustralia.org.au. (accessed 30 May 2018).
11. Australian Health Ministers' Advisory Council. Aboriginal and torres strait islander health performance framework 2014 report. Canberra: Australian Health Ministers' Advisory Council, 2015.

12. AlHW. Cardiovascular disease, diabetes and chronic kidney disease-Australian facts: Aboriginal and Torres Strait Islander people. Cardiovascular, diabetes and chronic kidney disease series. Canberra: AlHW, 2015.

13. Robertson J, Stevenson L, Usher K, et al. A review of trends in indigenous Australian tobacco research (from 2004 to 2013), its associated outputs and evidence of research translation. Nicotine Tob Res 2015;17:1039-48.

14. Ivers RG, Castro A, Parfitt D, et al. Evaluation of a multicomponent community tobacco intervention in three remote Australian Aboriginal communities. Aust N Z J Public Health 2006;30:132-6.

15. Virtanen M, Kivimäki M, Kouvonen A, et al. Average household income, crime, and smoking behaviour in a local area: the Finnish 10-Town study. Soc Sci Med 2007;64:1904-13.

16. van Lenthe FJ, Mackenbach JP. Neighbourhood and individual socioeconomic inequalities in smoking: the role of physical neighbourhood stressors. J Epidemiol Community Health 2006;60:699-705.

17. Andrews JO, Mueller M, Newman SD, et al. The association of individual and neighborhood social cohesion, stressors, and crime on smoking status among African-American women in southeastern US subsidized housing neighborhoods. J Urban Health 2014;91:1158-74.

18. Brady M. Historical and cultural roots of tobacco use among Aboriginal and Torres Strait Islander people. Aust N Z J Public Health 2002;26:120-4.

19. Macknight $\mathrm{C}$. The view from Marege': Australian knowledge of Makassar and the impact of the trepang industry across two centuries. Aboriginal History Journal 2011;35:121-43.

20. Webb L, Bambrick H, Tait P, et al. Effect of ambient temperature on Australian northern territory public hospital admissions for cardiovascular disease among indigenous and non-indigenous populations. Int J Environ Res Public Health 2014;11:1942-59.

21. Chandra S, Chaloupka FJ. Seasonality in cigarette sales: patterns and implications for tobacco control. Tob Control 2003;12:105-7.

22. Momperousse D, Delnevo CD, Lewis MJ. Exploring the seasonality of cigarette-smoking behaviour. Tob Control 2007;16:69-70.

23. Anderson CA. Temperature and aggression: ubiquitous effects of heat on occurrence of human violence. Psychol Bull 1989;106:74-96.

24. Anderson CA. Heat and violence. Curr Dir Psychol Sci 2001;10:33-8.

25. Choi D, Ota S, Watanuki S. Does cigarette smoking relieve stress? Evidence from the event-related potential (ERP). Int J Psychophysiol 2015;98:470-6.

26. Daniel M, Cargo MD, Lifshay J, et al. Cigarette smoking, mental health and social support: data from a northwestern First Nation. Can $J$ Public Health 2004;95:45-9.

27. Menzies School of Health Research. Improving the quality of primary health care - a primary training manual for the One21seventy cycle. Darwin: Menzies School of Health Research, 2014.

28. Australian Bureau of Statistics. Australian Standard Geographical Classification (ASGC). Canberra: Australian Bureau of Statistics, 2011.

29. Australian Bureau of Statistics. Census of population and housing - 2011 census products. Canberra: Australian Bureau of Statistics, 2011.

30. Department of Human Services. Co A, ed. 2013 Australian government indigenous programs \& policy locations (AGIL). Canberra: Department of Human Services, 2013.

31. Bureau of Meteorology. Climate data online. Canberra, Australia: Australian Government, Bureau of Meteorology, 2016.

32. Australian Government Bureau of Meteorology. Annual and monthly heating and cooling degree days 2018. 2018 http://www.bom.gov. au/climate/map/heating-cooling-degree-days/documentation.shtml (accessed 17 Dec 2018).

33. Stern H, de Hoedt G, Ernst J. Objective classification of Australian climates. Australian Meteorological Magazine 2000;49:87-96.

34. Berry G, Armitage P. Mid-P confidence intervals: a brief review. The Statistician 1995;44:417-23.

35. Wright A, Lovett R, Roe $Y$, et al. Enhancing national data to align with policy objectives: Aboriginal and Torres Strait Islander smoking prevalence at finer geographic levels. Aust Health Rev 2018;42:348.

36. AlHW. Tobacco indicators baseline data: reporting under the National Tobacco Strategy 2012-2018. Drug statistics series. Canberra: Australian Institute of Health and Welfare, 2015.

37. AlHW. The health and welfare of Australia's Aboriginal and Torres Strait Islander peoples: 2015. Canberra: Australian Institute of Health and Welfare, 2015. 
38. Homel R, Lincoln R, Herd B. Risk and resilience: crime and violence prevention in aboriginal communities. Aust $N Z J$ Criminol 1999;32:182-96.

39. 'yotti' Kingsley J, Townsend M, Phillips R, et al. "If the land is healthy... it makes the people healthy": the relationship between caring for Country and health for the Yorta Yorta Nation, Boonwurrung and Bangerang Tribes. Health Place 2009;15:291-9.

40. Memmot P, Stacy R, Chambers $C$, et al. Violence in Indigenous communities. Aboriginal environments research centre UoQ. Canberra: Commonwealth Attorney-General's Department, 2001.

41. Morrison K. Marx, Durkheim, Weber: formations of modern social thought. 2nd edn. London: Sage Publications Ltd, 2006.
42. Spencer DJ. Anomie and demoralization in transitional cultures: the australian aboriginal model. Transcult Psychiatry 2000;37:5-10.

43. Durkheim E. Suicide: a study in sociology. London: Routledge \& Kegan 2005, 1897

44. Graham H, Inskip HM, Francis B, et al. Pathways of disadvantage and smoking careers: evidence and policy implications. J Epidemiol Community Health 2006;60(Suppl 2):ii7-ii12.

45. Butler R, Chapman S, Thomas DP, et al. Low daily smoking estimates derived from sales monitored tobacco use in six remote predominantly Aboriginal communities. Aust N Z J Public Health 2010;34(Suppl 1):S71-5.

46. Rothman KJ. Modern epidemiology. Boston: Little, Brown \& Co, 1986. 